\title{
É a linguagem um dispositivo? (ou o linguista enrubescido)
}

Atilio BUTTURI Jr ${ }^{1}$

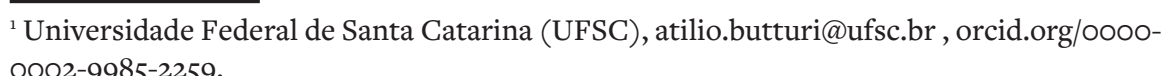
ooo2-9985-2259. 
RESUMO Neste ensaio, pretendo colocar em discussão a sugestão de Giorgio Agamben de que a linguagem funciona como um dispositivo, aproximando-a do que chamo de uma dramática saussureana a respeito da produção da Linguística como ciência geral da língua. Para tanto, recorro à problematização dos dispositivos e da assunção do conceito como ponto de viragem da arqueogenealogia foucaultiana, cujos efeito é forjar uma filosofia política baseada numa agonística entre o discursivo e o não-discursivo. No texto, então, volto-me para as análises que Agamben traça do estruturalismo e da teoria da enunciação benvenistiana, de modo a apontar no rubor e na vergonha uma modalidade de subjetivação que, em Saussure, materializa um desejo barrado, na emergência da Linguística, da inscrição autônoma do sistema. Dessa perspectiva, aproximo o rubor da hipótese de um dispositivo da linguagem, questionando-o sobre seus modos de subjetivação-dessubjetivação e sugerindo, por fim, a possibilidade de apontar, na rasura constitutiva em que se funda, as modalidades políticas de resistência e de liberdade que oferece.

ABSTRACT In this essay I intend to discuss Giorgio Agamben's suggestion that language functions as an apparatus, approximating language with what I call a Saussurean drama 
vis-à-vis academic articles on Linguistics as general science about language.To that end, I turn to the problematization of this apparatus and the assumption of the concept as a turning point in Foucaultian archaegenealogy, whose effect is to forge a political philosophy based on a distinction between the discursive and the non-discursive.In the text, then, I turn to the analyses that Agamben provides of structuralism and of the theory of Benvenistian enunciation in order to point out in the embarrassment a form of subjectivation that, in Saussure, materializes as a prohibited desire, in the emergence of Linguistics, for the autonomous registration of the system. From this perspective, I approach the embarrassment of the hypothesis of a language apparatus, questioning it as to its modes of subjectivation-unsubjectification and, finally, suggesting the possibility of pointing out, in the constitutive erasure on which it is based, the political modalities of resistance and freedom that it offers.

PALAVRAS-CHAVE Dispositivo. Linguagem. Enunciação. Resistências.

KEYWORDS Apparatus. Language.

Enunciation. Resistances. 


\section{Introdução}

Gostaria de começar este ensaio a partir de um dos discursos tradição moderna, qual seja, o da autoria. Poderíamos, de antemão, partir da própria noção de autoria com que pretendo produzir este texto, mas deixo uma certa metafísica da letra virà tona e aquele que conhecemos como Saussure cometer seu enunciado. O excerto que aqui tomo, para tanto, é de uma carta de 1894, endereçada a Meillet, que Giorgio Agamben (2012 [1977], p. 243, grifos meus) cita abundandemente em seus Estâncias:

Estou muito enojado com tudo isso e com a dificuldade que se tem em geral para escrever dez linhas que tenham sentido comum em matéria de fatos de linguagem. Preocupado há tempo sobretudo com a classificação lógica destes fatos... vejo cada vez mais a imensidão de trabalho que seria necessário a fim de mostrar ao linguista o que ele faz...e, ao mesmo tempo, quanto é vão tudo o que, afinal de contas, se pode fazer em linguística.

Parto de Saussure e vou ao segundo excerto, mais conhecido e quase célebre, desta vez de Michel Foucault. Trata-se do muito comentado trecho de O sujeito e o poder (1982), publicado nos Ditos e Escritos IX (FOUCAULT, 2014, p. 128, grifos meus):

Sem dúvida, o objetivo principal, hoje, não é descobrir, mas recusar o que nós somos. Devemos imaginar e construir o que poderíamos ser para nos livrarmos dessa espécie de "dupla obrigação" política que são a individualização e a totalização simultâneas das estruturas do poder moderno. Poder-se-ia dizer, para concluir, que o problema, ao mesmo tempo, político, ético, social e filosófico que se apresenta a nós, hoje, não é de tentar liberar o indivíduo do Estado e de suas instituições, mas de nos livrarmos, nós, do Estado e do tipo de individualização que a ele 
se prende. Precisamos promover novas formas de subjetividade, recusando o tipo de individualidade que se nos impôs durante vários séculos.

Retomemos Saussure e Foucault, o fracasso e a tarefa enunciados nos recortes. Ambos partem da recusa - seja de uma lógica da linguagem, seja de uma subjetividade que nos é afeta. Mais do que a negação que ambos solicitam, me interessa partir de seus enunciados e marcar: i) a linguagem e sua cientificidade barrada (voltarei a este ponto), como aparece em Saussure; ii) a liberação do sujeito em relação à imposição de um modo de ser, individual, de que fala Foucault.

A partir de Agamben e de sua retomada do conceito de dispositivo - ou de vários momentos do italiano em sua abordagem sobre a linguagem, o mundo e os viventes -, meu esforço aqui é o de ler a linguagem (ou a língua, me perguntoํ) na modalidade de um dispositivo. Para mim, é justamente esse conceito que permite, a um só tempo, recolocar o drama saussuriano das estruturas e da produção de uma ciência (que, parece, ainda nos afeta, sobretudo, no campo em que nos encontramos) e o problema levantado por Foucault de uma dessubjetivação como “objetivo principal”. Dito de outro modo, pretendo pensar: é a linguagem um dispositivo? Se é um dispositivo, quais seus modos de captura e de subjetivação? No limite, ainda, é possível pensar em resistências e práticas de liberdade na e com a linguagem? Há um espaço de dessubjetivação na plasticidade de um dispositivo da linguagem?

Não espero responder peremptoriamente a essas questões que, como se sabe, já animaram autores fundamentais para o século XX, de Heidegger a Derrida, de Agamben a Foucault. Para, porém, fazer minhas provocações, recorro a uma análise dos discursos sobre uma

\footnotetext{
${ }^{1}$ Ou língua(gem), se partirmos estritamente da leitura de Agamben, que acaba por açambarcar o conceito de língua no de linguagem.
} 
ciência da língua e sobre um dispositivo da linguagem, dividindo o ensaio em três breves partes. Na primeira, realizo uma apanhado em panorama sobre o conceito de dispositivo e sobre a possibilidade que avento de ler a linguagem como dispositivo. Na segunda, retomo algumas das leituras que a linguagem recebeu em Agamben e Foucault (aqui, novamente, não pretendo ser exaustivo). Na terceira, por fim, intento amarrar os fios e perscrutar os nós dessa rede que envolve um dispositivo e a promessa de formas de dessubjetivação.

\section{Esse perigoso dispositivo...2}

Passo à primeira parte e ao conceito de dispositivo3. Inicialmente,gostariadetrazeràtonacertomodoheideggerianodepensaras relações entre a modernidade e a técnica. Não pretendo, certamente, fazer uma história das origens ou das influências - nada mais antifoucaultiano do que isto. Com Agamben (2010a), apenas aponto para o caráter de emergência do conceito, em sua heterogeneidade, nos moldes definidos pela genealogia nietzschena. Assim, o processo de subjetivação, conforme lido em Foucault, teria como pressuposto uma leitura heideggeriana daquela espécie de "injunção de mediação" do mundo que, na modernidade, corresponderia ao cuidado com o ente e o abandono do ser (DUARTE, 2006). Heidegger, como se sabe, foi um filósofo central para Foucault ${ }^{4}$, que afirmava o papel do alemão em sua leitura de Nietzsche: “[...] Heidegger sempre foi para o mim o filósofo essencial. [...] Todo o meu futuro filosófico foi determinado por minha leitura de Heidegger. [...] Nietzsche com Heidegger foi um abalo filosófico! [...]” (FOUCAULT, 2010

\footnotetext{
${ }^{2}$ Remeto o leitor à Derrida (2008 [1967]) e ao perigo suplementar. Porém, para além de toda escritura. Nos dispositivos vamos encontrar posta a relação nunca saturável entre a linguagem e o mundo, o discursivo e o não-discursivo, condição de toda filosofia política da arqueogenealogia de Foucault.

${ }^{3}$ Para uma leitura do conceito, ver Butturi Junior (2016).

${ }^{4}$ Deleuze (2005 [1988], p.115) reconhece uma dívida: "Há uma redescoberta final de Heidegger em Foucault".
} 
[1984], p.259). Vamos reencontrar enunciados sobre a técnica e a modernidade de Heidegger (como parte do da existência do Dasein), devidamente deslocados, tanto em Foucault quanto em Agamben', aqueles cujos conceitos de dispositivo me interessam.

Do que se trata, então, quando pensamos num dispositivo como uma armação necessária para a produção de sujeitos, uma rede sobre a qual nos lançamos irremediavelmente? O conceito, como se sabe, teve pouco detalhamento em Michel Foucault, não obstante sua utilização tenha sido recorrente. Dessa perspectiva, ainda que um dos capítulos de A Vontade de Saber carregue o título de O dispositivo de sexualidade (FOUCAULT, 2009b), é em numa entrevista à International Psychoanalytical Association, em 1977, que Foucault elabora, em linhas gerais, o que compreende pelo conceito:

Através deste termo tento demarcar, em primeiro lugar, um conjunto decididamente heterogêneo que engloba discursos, instituições, organizações arquitetônicas, decisões regulamentares, leis, medidas administrativas, enunciados científicos, proposições filosóficas, morais, filantrópicas. Em suma, o dito e o não dito são os elementosa do dispositivo. $O$ dispositivo é a rede que se pode estabelecer entre estes elementos.

Em segundo lugar, gostaria de demarcar a natureza da relação que pode existir entre estes elementos heterogêneos. [...] Em suma, entre estes elementos, discursivos ou não, existe um tipo de jogo, ou seja, mudança de posição, modificações de funções, que também podem ser muito diferentes.

Em terceiro lugar, entendo dispositivo como um tipo de formação que, em um determinado momento histórico, teve como função principal responder a uma urgência. $\mathrm{O}$ dispositivo tem, portanto, uma função estratégica dominante. (FOUCAULT, 2009a, p. 244).

${ }^{5}$ Ver, por exemplo, as menções a Gestell heideggeriana em Agamben (2014a). 
O trecho é muito conhecido e nele Foucault (2009a) ainda afirma que a constituição dos dispositivos obedeceria a dois processos: o primeiro, na forma de um a priori, o de "sobredeterminação funcional" em relação à dispersão de seus elementos e aos demais dispositivos; o segundo, diretamente político, de "preeenchimento estratégico", entendido como o mecanismo plástico de reutilização dos dispositivos a partir de novas urgências históricas. O dispositivo, conforme elaborado por Michel Foucault, seria uma rede complexa e relacional, constituído de um campo de visibilidades, que permite fazer emergir objetos que se dão a ver conforme critérios específicos; e de um campo de enunciações, que estratificam o visível em regimes de dizer; de linhas de força, relacionadas ao poder-saber e às estratégias e às urgências a que ele responde (DELEUZE, 2005 [1986], 1990).

Ora, a relação sempre aberta entre um campo de dizibilidade e um de visualidade - proposta de Deleuze (2005 [1986]) - para inteligir a genealogia ganhou de Negri (2016) uma leitura em que o conceito de dispositivo (assim como a biopolítica e o biopoder) passa à boca de cena, por levar ao limite a exigência deleuziana de um pensamento sobre o campo da imanência e a agonística entre discurso e exterioridade. Para ele, "O dispositivo é uma operação não apenas epistemológica, mas também ontológica, que reconstrói oreal a partir de baixo, em situação, segundo uma pragmática orientada.". (NEGRI, 2016 [2003], p. 101).

É nesse espaço em que a linguagem (de uma perspectiva discursiva) e o mundo (de uma perspectiva genealógica) se encontram, se evocam e conjuram um ao outro que um dispositivo pode surgir, como rede de captura e produção de sujeitos. Giorgio Agamben foi um dos que, a partir de Foucault, valeu-se do conceito que tomou como central para definir a arqueogenealogia-parapensar justamente essa produção de sujeitos no interior de tecnologias 
disciplinares e tecnologias biopolíticas de governo. Agamben (2014a [2005]) fará uma conferência na Universidade Federal de Santa Catarina, em 2005 (e atualmente muito célebre) cujo título era O que éum dispositivo?.

Não me deterei nas discussões que ele tece ao descrever o dispositivo como um vértice entre os viventes e o mundo, cujo resultado é a produção de sujeitos - viventes sempre capturados. No entanto, dois pontos precisam ser considerados: o primeiro, que Agamben sustenta que à proliferação dos dispositivos corresponde, a um só tempo, a multiplicação de modalidades de subjetivação e de dessubjetivação - não há garantia de usos corretos dos dispositivos e, portanto, nem do controle irrestrito e nem de um sujeito saturado de identidade. Segundo, o que aqui me interessa diretamente, a sugestão de que a linguagem ${ }^{6}$ funcionaria como um dispositivo. Cito o italiano:

Generalizando posteriormente a já bastante ampla classe dos dispositivos foucaultianos, chamarei literalmente de dispositivo qualquer coisa que tenha de algum modo a capacidade de capturar, orientar, determinar, interceptar, modelar, controlar e assegurar os gestos, as condutas, as opiniões e os discursos dos seres viventes. Não somente [e ele cita os clássicos de Foucault], mas também a caneta, a escritura, a literatura, a filosofia, a agricultura, o cigarro, a navegação, os computadores, os telefones celulares e - por que não - a própria linguagem, que talvez é o mais antigo dos dispositivos, em que há milhares e milhares de anos um primata provavelmente sem se dar conta das consequências que se seguiram - teve a inconsciência de se deixar capturar. (AGAMBEN, 2014a [2005], p.39-40, grifos meus).

\footnotetext{
${ }^{6}$ Linguagem e língua não são sempre distinguidas em Agamben, que parece se preocupar menos com uma ciência linguística per se, mas com os efeitos que a linguagem pode estabelecer (como dispositivo, ela seria a um só tempo autônoma é constituída pela exterioridade, afinal) nos sujeitos e no mundo.
} 
Se há na modernidade uma pulverização dos dispositivos, que passam a ser recorrentes e ubíquos, a questão lançada é: por que não pensar a própria a linguagem como dispositivo ${ }^{7}$, já que é ela a condição de subjetivação incontornável a que nos submetemos? Na genealogia agambeniana, entre os viventes e o mundo estão os dispositivos como garantia de captura e condição de existência. Dessa perspectiva, os deslocamentos que a linguagem ofereceu para o próprio conceito de vivo devem ser levados em consideração, na forma em que aparecem em Agamben (2010 [1995]), quando o autor apresenta suas conhecidas cisões: entre zoé e bios, uma vida natural não-qualificada e outra, política e humana; entre a voz que pertence a todos os viventes e sua passagem para a qualificação humana da linguagem; entre o grito caótico e a ordem sintagmática da fala. A cisão biopolítica em que a linguagem tem lugar é tomada da Política de Aristóteles:

Só o homeme entre os viventes possui a linguagem. A voz, de fato, é sinal da dor e do prazer e, por isto, ela pertence também aos outros viventes (a natureza deles, de fato, chegou até a sensação da dor e do prazer e a representá-los entre si), mas a linguagem serve para manifestar o conveniente e o inconveniente, assim como também o justo e o injusto; isto é próprio do homem com relação aos outros viventes [...] (ARISTÓTELES 1253a, 10-18 apud AGAMBEN, 2010 [1995], p. 15, grifos meus).

Interessa a Agamben, como se vê, apontar que a política funda a metafísica ocidental na medida em que separa formas de vida. A separação, porém, diz respeito diretamente aos modos em que a

7 Aqui, não farei distinção entre um dispositivo da linguagem e o funcionamento da linguagem como dispositivo. Primeiro, porque - não obstante o efeito de "como", lido, por exemplo, pela $\mathrm{AD}$ francesa no casao de Lacan -, parto da leitura de Agamben, que não distingue esses efeitos e, ainda, sustenta a tese de uma ontologia e de uma epistemolgia, relacionais e ubíguas. Ora, dessa perspectiva, gostaria - ainda - de entender, no limite das distinções possíveis sugeridas pelo "como" uma das modalidades do dispositivo, qual seja, a da ausência de garantia de êxito de seus regimes de objetivação e de subjetivação. 
linguagem habita os seres, pois entre os homens (bios) e os outros seres (zoé) se funda uma relação de oposição. Homem, afinal, é aquele que "[...] na linguagem, separa e opõe a si próprio a vida nua e, ao mesmo tempo, se mantém em relação a ela numa exclusão inclusiva." (AGAMBEN, 2010 [1995], p. 16).

Pensar a linguagem nesse dispositivo de produção de subjetividade, em Agamben, será operar na dimensão da exceção, a exclusão inclusiva das modalidades de vida: zoé, ao mesmo tempo que desqualificada e excluída do ordenamento jurídico e político porque vida nua, é capturada na exceção tanatopolítica; bios é tornada vida capaz de linguagem e de logos, qualificada na cidade dos homens. Essa dimensão da soberania na origem da política - a exclusão inclusiva não seria uma condição de pensar os modos pelos quais podemos e pudemos nos tornar sujeito? Ser sujeito, nesse caso, é uma possibilidade que apenas a linguagem oferece? Dito de outro modo e a partir da indagação do presente ensaio: se a linguagem é o mais antigo dos dispositivos, ela significa sempre exclusão e manutenção da fissura inaugural, ou seja, a assunção da ordem e da estrutura da política se inscreve na linguagem mas, em contrapartida, coloca em funcionamento fantasmático aquilo que é da ordem da zoé, da voz e do grito?

Faço aqui um corte e inicio a relação entre a (bio)política e a linguagem, de um lado, e o problema saussureano de invenção de uma ciência, a Linguística, a partir da invenção de um objeto, a língua, na modalidade da exceção. A hipótese que defendo é a seguinte: se o dispositivo exige o vértice entre a linguagem e a exterioridade (pressuposta no caráter discursivo e não-discursivo), o problema saussureano seria justamente o de hipostasiar uma parte desse dispositivo a partir do corte. Nesse caso, a dramática saussureana seria fundamentalmente bio-política: porque produzida na estrutura da exceção, porque ainda solicitando uma resposta para os problema do vivo e da vida. 
É sobre a leitura dessa dramática da linguagem que pretendo me deter a seguir.

\section{A língua e o rubor}

É hora, pois, de pensar nos modos pelos quais esse dispositivo da linguagem opera na invenção da Linguística moderna. Para tanto, parto de três textos de Agamben em que a linguagem e a linguística, propriamente saussuriana, estão em questão: Estâncias, de 1977; o Homo sacer I, de 1995; O que resta de Auschwitz (o Sacer 3), de 2008. Estou aqui considerando a provocação de Agamben (2014a [2005]), qual seja, a de que linguagem é um dispositivo, a fim de ler o problema político que reaparece nas muitas ocasiões em que o filósofo pretende refletir sobre ela - ao que parece, no esforço de deslindar seu fincionamento e aquilo que oferece como modos de captura para viventes.

Vou ao primeiro dos textos, em que a discussão é sobre uma fórmula cara aos linguistas, psicanalistas, antropólogos etc e que marca o estruturalismo e as leituras sobre o sujeito: $\mathrm{S} / \mathrm{s}$. Na quarta parte de Estâncias, intitulada A imagem Perversa: a semiologia do ponto de vista da esfinge, Agamben (2012 [1977]), similar ao que fez Foucault algumas vezes (em A Vontade de Saber, em A Verdade e as Formas Jurídicas, por exemplo), dá uma leitura linguageira para a tragédia edipiana: mais do que o incesto, o problema de Édipo foi o de pretender solucionar a linguagem na forma de um enigma passível de decodificação. Eis sua perdição.

O que Édipo, na leitura agambeniana, faz notar é aquilo que Hegel, nas Lições de Estética, vislumbrava: o SIMbólico é também o DIAbólico (o livro de Agamben é, aliás, sobre fantasmas e assombrações). A fratura se dá justamente pela ambiguidade da linguagem em relação à presença: ao mesmo tempo em que pretende trazê-la à materialidade, redunda num fracasso em que a 
materialização é sempre uma exclusão, um impedimento. Dito de outro modo, essa fratura que funda a linguagem - e que Agamben (2012 [1977], p. 219) considerada que "ficou afastada e ocultada" da história da metafísica diz respeito à uma relação nunca saturada, que diz respeito tanto à empresa de captura do mundo pela linguagem (seu caráter referencial) quanto à tentativa de captura do sujeito de uma enunciação (seu caráter discursivo).

Como em Lacan ou em Derrida - lembremos, o texto é de 1977, quando o ocaso do estruturalismo era bastante evidente -, Agamben (2012 [1977], p.221) descreve a metafísica moderna solicitada em Hegel como "esquecimento da diferença originária entre significante e significado". Nessa esteira aporética, se a filosofia contemporânea é filha do linguistic turn, Agamben retoma o esquecimento do Ser heideggeriano, mote se Ser e Tempo (e, como afirmei antes, espaço de destruição da metafísica de que se serviu também Foucault) e passa a pensar Saussure em seu paradoxo, o mesmo que o genebrino confessava a Meillet e com que abri este escrito: é possível fazer uma linguística? O signo saussuriano, bipartido, não inauguraria a história feliz de uma unidade de significação e de apaziguamento, mas a impropriedade sempre-já presente na "unidade dupla" do Cours e, no limite, na expulsão dos elementos demandados por uma linguagemdispositivo.

O problema do esquecimento do Ser heideggeriano, como se sabe, é o que condena a filosofia ao sono metafísico, mas também a condição positiva de uma ontologia fundamental, a ser realizada a partir da pergunta sobre o Ser do ente (HEIDEGGER, 1997 [1927]). O esquecimento de Agamben é também o apontamento de um fracasso e a júbilo discreto de uma promessa em aberto: o pensamento sobre a linguagem ainda não tomou consciência dessa fratura inaugural, porque a Linguística parte do signo saussureano positivo e se esquece da diferença, apagando-a em nome da totalidade. A tarefa é descrever a fratura e reaver a complexidade do dispositivo. 
Agamben (2012 [1977], p. 244) lê na letra do Cours a aporia da unidade positiva do signo. Ele retoma a afirmação saussureana de que, não obstante as diferenças, no signo a positividade é garantida. Nas palavras de Saussure, citadas por Agamben (grifos meus): "Graças ao fato de que tais diferenças se condicionam umas às outras, teremos algo que pode se assemelhar a termos positivos [...].". Quanto às cartas a Meillet, elas corroboravam o impasse de qualquer ciência da linguagem, porque a desconfiança primeira era relativa justamente a esse "ponto de irradiação positivo em toda a linguagem" (SAUSSURE, 1894 apud AGAMBEM, 2012 [1977], p. 244, grifos meus), problema central de uma teoria das diferenças. Ora, o Cours, segundo Agamben, inauguraria a Linguística somente na condição de assumir o impasse; novamente, Agamben evoca o Cours para apresentar o paradoxo: "O que seria necessário para que tal relação entre o significante e o significado fosse dado em si? Sobretudo seria necessário que a ideia fosse determinada previamente e ela não é." (SAUSSURE, 1967, p. 272 apud AGAMBEN, 2012 [1977], p. 244, grifos meus $)^{8}$.

O que Saussure oferece, apesar de seus esforços, é uma “[...] ciência dos signos na metafísica." (AGAMBEN, 2012 [1977], p. 246). $\mathrm{O}$ ponto de vista agambeniano quer tanto colocar em suspenso a semiologia quanto sua crítica radical, a gramatologia. Para Agamben (2012 [1977]), até mesmo Derrida redunda em metafísica, pois ao restaurar a escritura significante e interpretar a fratura, deixa de notar o fato de que há sempre a dobra. Derrida, sob tal viés, é, ainda, o arauto de uma metafísica negativa e não sua superação. Agamben pretende que é o barramento do algorítimo saussureano a topologia da dobra, aquilo que permanece barrado, na origem da linguagem,

\footnotetext{
${ }^{8} \mathrm{Na}$ edição brasileira do Cours, a discussão aporética de Saussure está no capítulo O Valor Linguístico, mais exatamente no parágrafo quarto. O trecho em questão: "Mas dizer que na língua tudo é negativo só é verdade em relação ao significante e ao significado tomados separadamente: desde que consideremos o signo em sua totalidade, achamo-nos perante uma coisa positiva em sua ordem." (SAUSSURE, 1972 [1916], p.139, grifos meus).
} 
à significação. Significante e significado, para Agamben, devem ser substituídos pelo minimalismo da barra, a aporia inaugural que constitui toda possibilidade de uma linguagem - de um dispositivo da linguagem, eu diria aqui.

A modalidade da dobra reaparece no segundo dos textos que aqui escolhi para reflexão, o Homo Sacer, onde o problema da linguagem vai ser perscrutado segundo uma leitura da soberania. Novamente, trata-se de pensar a ambiguidade constitutiva da invenção do dispositivo no campo da ciência. Com Schmitt, Agamben vai descrever a soberania como a capacidade de produzir exceção. Assim, lendo os contruatualistas, como Hobbes, a fundação do governo só existia pela criação do Leviatã a partir do desejo dos súditos, o que, por conseguinte, redundaria numa excessão constitutiva - os súditos passam a ter outra qualidade, o soberano passa a operar sobre ele, precedendo-os e criando o direito que, no limite, é de morte. É esse paradoxo de algo que está, ao mesmo tempo, dentro e fora da lei, o que constituiria tanto o direito soberano quanto as relações extremas de um ordanamento rompido desde a origem - e daí o paradigma é o do campo de concentração, postulado de Agamben (2010b [1995]).

O funcionamento da norma jurídica como exceção é, então, aproximado da langue saussureana. No funcionamento do sistema proposto por Saussure9, segundo Agamben (2010b [1995]), aquilo que é paradoxal na soberania revela-se na condição de existência da linguística moderda. Ora, o não-linguístico opera como aquilo que, de outra natureza (como o Leviatã) mantém o próprio linguístico (a estrutura). Aqui, é o não-jurídico (a soberania como estado absoluto) que funda a lei, ainda que o esforço seja o de expulsar o caráter referencial. É a exceção de uma estrutura de exclusão-inclusiva, que Hegel (novamente ele) já havia apontado: a linguagem está sempre dentro e fora de si mesma.

9 Cabe notar em Agamben (2010b [1995]) uma leitura da Linguística saussureana que oblitera a cisão entre langue e parole e a pensa em sua ambiguidade. Quando diz linguagem, o autor remete ao irresolvível em Saussure, aquilo que se mostra na modalidade da dobra. 
Interessa a Agamben, na ligação entre direito e linguagem, observar que, no nosso tempo, é a exceção a estrutura fundamental, em sua ambiguidade assassina. Como no problema levantado por Saussure e discutido em Estâncias, a dramática da linguagem é o seu modo paulino do "como se" coincidir sentido e referente ou fazer crer numa langue que só existe na condição soberana da exceção que inventa suas normas. Agamben (2010b [1995], p. 28, grifos meus) arremata que há, por conseguinte, um vínculo entre uma norma biopolítica e o dizer - o que evoca, por sua vez, sua provocação acerca de um dispositivo da linguagem no qual a aporia entre o linguístico e o não-linguístico é axial:

A linguagem é o soberano que, em permanente estado
de exceção, declara que não existe um fora da língua,
que ela está sempre além de si mesma. A estrutura
particular do direito tem seu fundamento nesta
estrutura pressuponente da linguagem humana.
Ela exprime o vínculo de exclusão inclusiva ao qual
está sujeita uma coisa pelo fato de encontrar-se na
linguagem, de ser nominada. Dizer, neste sentido, é
sempre jus dicere.

Essa linguagem e o direito, o direito de dizer na constituição da norma - que é exceção e, no limite, tecnologia da tanatopolítica -, eis o que gostaria de retomar, mais esta vez, na modalidade do dispositivo. No Homo Sacer, a descrição da linguagem sausssureana, defendo, exige o pressuposto da relação ambígua entre linguístico e o não-linguístico. Mais ainda: segundo a captura do vivente e de acordo com um deslocamento da desordem para a ordem - o que lemos no Estâncias na produção de uma linguagem propriamente humana -, esse dispositivo é sempre um vértice entre a política e a vida. Viver e dizer, pois, são elos do dispositivo da linguagem que apontam para

${ }^{10}$ O modo paulino do "como se", estrutura de dizer e de viver de uma estética da existência e uma resistência pode ser lido em Agamben (2014b, 2000). 
a exceção soberana, cindindo modalidades de vida, modalidades de dizer e de produzir sentido.

Finalmente, passo à terceira leitura da Linguística de Agamben, empreendida ema $O$ que resta de Auschwitz, seu belo texto sobre a possibilidade do testemunho, sobre a exceção, sobre Primo Levi e sobre esse paradigma do campo em que vivemos - muçulmanos ou não (o muçulmano, esse vivente cuja subjetividade está posta em xeque na tanatopolítica). Agamben (2008), já no início do texto, remete-nos à vergonha, para questioná-la na relação com os sujeitos e a ética. Ora, aqui cabe retomar o próprio Saussure, para quem a vergonha sondava a ciência. Repito o trecho com que iniciei este ensaio, a carta a Meillet, de 1894: "Estou muito enojado com tudo isso e com a dificuldade que se tem em geral para escrever dez linhas que tenham sentido comum em matéria de fatos de linguagem" (AGAMBEN, 2012 [1977], p.243, grifos meus). Esse nojo, gostaria de ler justamente no funcionamento da vergonha, do rubor a que Agamben faz menção e que em Saussure corrobora aquilo que avento como a dramática da linguagem. A aproximação, nesse caso, não pretende evitar a diferença entre nojo e vergonha, mas apontar as relações entre o enunciado e o sujeito, da ordem de uma disjunção e de uma reaparição fantasmática, inscrita no corpo.

Agamben (2008) recorre à vergonha para pensar na figura do sobrevivente do campo, cuja vida perdeu a dignidade diante do ocaso da morte e da impossibilidade do testemunho. O autor problematiza a vergonha do sobrevivente do campo e usa, para tanto (entre muitos, como Kant, Heidegegr ou a experiência SM), um texto de Levinas, de 1935, para quem a vergonha, o ruborizar-se, é a condição radical da presença de si a si mesmo. No limite, é nossa incapacidade de nos dessolidarizarmos conosco, mas uma nudez de si que implica um olhar para si, sem controle. Similar à estrutura da exceção, a vergonha traz no bojo um inassumível, algo que nos exige numa exclusão inclusiva, 
qual seja: uma dessubjetivação que reside em nós mesmos: “[...] este inassumível não é algo exterior, mas provém da nossa intimidade; é aquilo que em nós existe de mais íntimo (por exemplo, a nossa própria vida fisiológica." (AGAMBEN, 2008, p.110, grifos meus). A vergonha seria a modalidade de subjetivação dessubjetivada. Um movimento de desconcerto e de deslocamento dos efeitos de identidade que rondam o sujeito. Mais, ainda, seria - e o exemplo de Agamben não é sem motivo - algo que retoma a ambiguidade entre as modalidades de vida, bios qualificada e zoé fisiológica que vem à tona apontando a ambiguidade de nossas capturas por dispositivos.

Por que a vergonha, aqui, quando o que faço é ler a possibilidade de um dispositivo da linguagem? Para além do rubor saussureano, a que voltarei, a estrutura da vergonha reaparecerá na linguagem. Ao tratar da criação poética, Agambem (2008, p.118) retomar a dessubjetivação na composição, talvez, de "todo ato de palavra". Logo a seguir, ele se vale da Carta de Paulo aos Coríntios e à glossolalia: o acontecimento da palavra misteriosa, o falante que enuncia "coisas misteriosas" que não controla, porque sua origem está num outro. É o bárbaro que funda essa glossolalia. Bárbaro, como ensina Agamben (2008), é aquele que é sem logos (da ordem do grito, da voz e da zoé), o estrangeiro que habita a capacidade de enunciação e que aponta: i) para o acontecimento de uma dessubjetivação; ii) para um fracasso em toda tentativa de estruturação da linguagem.

É, pois, de um fracasso e um rubor que, ao retomar o problema estruturalista, Agamben vai observar na teoria enunciativa de Benveniste. É a dessubjetivação que interessa a Agamben (2008): a vergonha e a falta de controle de uma enunciação que se vê nua; e, mais importante, a cisão entre língua e discurso de Emile Benveniste. Para Benveniste, como é de muito sabido, os embreantes, o sistema dêitico, no mesmo golpe em que marcam a dependência do sujeito que habita na linguagem (é, afinal, o eu quem cria o tempo e o espaço), 
estabelece um paradoxo de muito conhecido, similar ao apontado por Hegel: passar da língua ao discurso, o sujeito passa a existir apenas na condição de falar na língua. Essa expropriação, segundo Agamben (2008), é a marca da glossolalia , digamos, original.

Leiamos Benveniste (2005 [1958], p. 288), que fala de uma "revelação da subjetividade na linguagem". Agamben (2008), por sua vez, afirma que Eu falo, nos termos de Benveniste, traz no bojo a responsabilidade do dizer mas, em contrapartida e ambiguamente, o funcionamento de uma vergonha: falo no interior de um diz$\mathbf{s e}^{11}$. Sou sujeito na expropriação, barrado, porque meu dizer exige a dessubjetivação na linguagem. Quando Benveniste pretende que o eu refere-se apenas "[a] algo muito singular, que é exclusivamente linguístico [...]” (BENVENISTE (2005 [1958], p. 288, grifos meus), o que temos, para Agamben (2008), é a experiência radical da glossolalia e daquela exclusão inclusiva produzida na (bio)política. No discurso, aquilo que a linguística saussureana materializava como um problema a conjurar se materializa na coincidência entre subjetividade e dessubjetivação. No discurso, ainda, o vivo e o enunciável se confundem até o limite do silêncio:

No presente absoluto da instância do discurso, subjetivação e dessubjetivação coincidem em todos os pontos, e tanto o indivíduo em carne e osso quanto o sujeito da enunciação se calam totalmente. Isso também pode ser expresso dizendo que quem fala não é o indivíduo, mas a língua; isso, porém, nada mais significa senão que - não se sabe como - a palavra atingiu uma impossibilidade de falar. (AGAMBEN, 2008, p. 121, grifos meus).

\footnotetext{
${ }^{11}$ Em Benveniste (2005 [1958], p. 288-289): “A linguagem está de tal forma organizada que permite a cada locutor apropriar-se da língua toda designando-se como eu." [...] "A linguagem é, pois, possibilidade da subjetividade, pelo fato de conter sempre as formas lingüísticas [sic] apropriadas à sua expressão; e o discurso provoca a emergência da subjetividade $[\ldots] "$.
} 
É na instância desse "não se sabe como" que operam os poetas: uma responsabilidade diante do dizer e do ser sujeito na língua; uma vergonha da constituição pela língua, da qual não é possível se desnvincular e que torna toda enunciação, a um só tempo, pertença e não pertença. Agamben (2008, p. 123) assevera que é a poesia moderna o terreno em que emerge a dessubjetivação cuja estrutura é a do discurso. Fernando Pessoa marcaria um percurso de despersonalização e de retorno a si mesmo, pois sua heteronomia solicita que possa “[...] responder por sua dessubjetivação."

Ora, aqui a topologia dos três textos de Agamben pode ser retomada, num itinerário: primeiro, uma Linguística cuja condiçãoéa dobra; depois, a constatação de que a linguagem, conforme Saussure, guarda em si a estrutura da exceção soberana; por fim, o discurso e a presença de sujeito como resto entre a captura da linguagem. Nos três casos, o ponto fulcral é a pergunta sobre a natureza dos estudos sobre a linguagem, aquela mesma que preocupava e enrubescia Saussure - um nojo. Em jogo, está a cisão que torna possível toda a política, qual seja: entre as modalidades de vida, bios e zoé, e a consequente produção da exceção.

A possibilidade de matar - de sacrificar o insacrificável - e de produzir a vida nua, como tentei até aqui mostrar, é um problema da norma jurídica, desde que essa é também direito a dizer. Nesse cadinho, os viventes, as normas e a linguagem guardam relações não irrelevantes. Para uma teoria biopolítica, um dispositivo da linguagem. Isso equivale a pensar a dobra, a exceção e o rubor. $\mathrm{O}$ linguista ruborizado, tal qual Saussure em queixa a Meillet, coloca em xeque o empreendimento de uma ciência e aponta no seu fracasso a possibilidade de um êxito de outra ordem. Dessubjetivado, tornado corpo político (e corporalizando os sujeitos que falam e que cometem discurso), o que parece mais importante aqui, realinhando a investigação sobre a linguagem na consideração mesma de que ela é: dispositivo. 
$\mathrm{Na}$ última parte deste texto, gostaria de me voltar para aquilo que, de resistência, um dispositivo da linguagem passa a sugerir.

\section{0 sem remédio}

A leitura que Agamben sobre a Linguísitca mostra a tensão existente numa teoria que reduz o acontecimento à formalização. A pergunta pela enunciação benvenistiana, nesse caso, ainda reverbera, segundo a ordem de um ato "absolutamente singular e irrepetível" (AGAMBEN, 2008,p.140), que escapa dogolpe científico de produção de um objeto no interior do dispositivo ambíguo da linguagem. Dito de outro modo, a aporia de Benveniste funcionaria como a marca de uma impossibilidade semiótica e uma exigência positiva - a que Michel Foucault, de alguma maneira, teria respondido com a sua teoria dos arquivos, a arqueologia ou a que Agamben (2010a) formulou em sua ruinologia. Para Agamben (2008), Foucault, na Arqueologia, teria realizado o programa de uma metassemântica benvenistiano, ao tomar como objeto de investigação justamente o excedente semiótico, o "mais" que separa uma análise linguística de sua arqueologia dos discursos.

Diferente do que acontecia em Benveniste, Agamben (2008) considera que a retomada do esforço da Semiologia Geral saussuriana, realizado pela metassemântica de Benveniste e pela arqueologia de Foucault, no mesmo 1969, diferem quanto ao papel dado ao sujeito. Para Agamben (2008), a arqueologia parte da dessubjetivação e evoca a existência dos enunciados no limite entre a langue e a parole. $\mathrm{O}$ discurso, para Foucault, restaria irresolvível entre a repetibilidade e o acontecimento político, entre o dito e o não-dito estratégico, revelando a um só tempo a sistematividade e a dispersão que habita aquilo que existe em linguagem. Para o arqueólogo-positivista, o interesse era descrever algo "no limite da linguagem" (FOUCAULT, 2012 [1969], p. 127). Como na explicação sobre a filosofia política da 
arqueolgia de Deleuze (2005 [1986]), o que Foucault ofereceria é da ordem dos dispositivos e da relação entre o dizível, as estratégias de poder, as tecnologias e as formas de subjetivação.

Chamo a atenção, a título de conclusão, para aquilo que é, também em Michel Foucault, da ordem da dessubjetivação, motivo de investigação de Agamben. Faço um retorno breve ao Foucault inicial: "Sem dúvida, o objetivo principal, hoje, não é descobrir, mas recusar o que nós somos". Ora, é a relação pretendida por Agamben, referente à dessubjetivação presente em toda subjetivação que aqui reaparece, mas tomada como vislumbre de práticas de liberdade e de resistência. Dito de outro modo, se o dispositivo da linguagem é dobra que captura viventes, é na estrutura de inclusão exclusiva, como aporia e ambiguidade fundante, que nos tornamos algo cuja origem é a capacidade da recusa. Resistir, nesse caso, é uma condição aberta para aquilo que, como resto, aparece entre a norma, a exceção e a linguagem.

Brevemente, arremato, lembrando a vergonha de Saussure e a tarefa de Foucault da Introdução deste ensaio. É um já constumeiro Agamben (1993, p.83) - dessa vez no A comunidade que vem - que cito:

Apenas podemos ter esperança naquilo que é sem remédio. Que as coisas estejam assim ou de outra maneira - isto é ainda no mundo. Mas que isso seja irreparável, que o assim seja sem remédio, que nós possamos contemplá-lo como tal - isso é a única passagem para fora do mundo. (O caráter mais íntimo da salvação: que sejamos salvos só no instante em que já não queremos sê-lo). Por isso, nesse instante, existe salvação - mas não pra nós).

Saussure, o linguista enrubescido de que falei, parece na condição de provar essa salvação que é pharmakon ${ }^{12}$ o o que salva e o que dana. Interessa, mais do que a anedota, interrogar sobre aquilo que, ainda

${ }_{12}$ “[...] ‘esse phármakon, essa ‘medicina', esse filtro, ao mesmo tempo remédio e veneno, já se introduz no corpo do discurso com toda ambivalência.” (DERRIDA, 2005, p. 14). 
nos estudos sobre a linguagem, é da ordem da dessubjetivação e das resistências e que diz respeito à política. É na intersecção entre um acontecimento e uma prática política, na urgência histórica e estratégica, que têm lugar as coisas da linguagem. Esse dispositivo é sempre, segundo a leitura que aqui aventei, pertença e não pertença. Como uma norma e não como uma lei, a linguagem é aquilo que, inventado, permance a engendrar modalidades de sujeito e de vida. Por isso, é um dispositivo de captura e, no limite, de exceção e de fazer morrer. Porém, se é sem remédio, é também uma dobra aberta de que nos valemos para resistir. É dessa salvação que, como afirmava Holderlin, nasce do perigo, é que parece se tratar quando pretendemos, dessubjetivados, travas lutas corpóreas e fazer gestos ínfimos em seu interior rasurado - esse dispositivo primeiro e plástico que nos solicita.

\section{Considerações finais}

Neste ensaio, parti de uma espécie de pergunta, recorrente e em aberto, forjada por Giorgio Agamben a partir de Michel Foucault: a linguagem, afinal, é um dispositivo? Ao me deparar com o questionamento, voltei-me à presença de uma discussão sobre a linguagem na filosofia do italiano, mais detidamente naquela em que a fundação da linguística moderna é explorada em sua invenção rasurada.

Nesse itinerário, depois da leitura dos apontamentos sobre a positividade do signo, a exceção soberana da língua e a aporia na teoria enunciativa, assumi que: i) se a linguagem é um dispositivo, é preciso pensá-la na modalidade da política; ii) a política, nesse caso, é um modo de captura que se funda na exclusão inclusiva e que cria formas de vida mais ou menos qualificadas; iii) nessa biopolítica, os 
dispositivos aparecem como relação ambígua entre o linguístico e o não-linguístico;iv) nesse caso, e paradoxalmente, pensar a linguagem como dispositivo solicita que a relação de conjunto seja colocada em causa, porque ela é ao mesmo tempo o que captura (o dispositivo) e uma das formas da captura (o discurso) ${ }^{13}$.

Tendo em vista o que discuti e o relacionado entre i e iv, do que se trata quando interrogamos um dispositivo da linguagem? Ao que parece, da assunção do rubor como um voltar-se para si. Essa vergonha, positiva, faz inquirir acerca daquilo que, como gesto corriqueiro, expulsamos: o corpo e o discurso, a produção de modos de sujeito em tecnologias nas quais a linguagem tem destaque, a deiscência dos esforços de saturação. É, pois, na dobra e no hífen sobre os quais algumas linguísticas têm se debruçado, com mais ou menos êxito - que se dá a ver uma política linguística ou, de forma mais fundamental, uma linguagem-política.

\section{Referências}

AGAMBEN, G. O amigo. O que é um dispositivo?. Tradução de Vinícius Nicastro Honesko. Chapecó: Argos, 2014a.

AGAMBEN, G. Altíssima pobreza: regras monásticas e formas de vida. Tradução de Selvino J. Assmann. São Paulo: Boitempo Editorial, 2014b.

AGAMBEN, G. Estâncias: a palavra e o fantasma na cultura ocidental. Tradução de Selvino J. Assman. Belo Horizonte: Editor da UFMG, 2012. [1977].

AGAMBEN, G. Signatura rerum: sobre el método. Tradução de Flavia Costa y Mercedes Ruvituso. Barcelona: Editorial Anagrama, 2010a.

AGAMBEN, G. Homo sacer I: o poder soberano e a vida nua. Tradução de Henrique Burigo. 2. ed. Belo Horizonte: Editora da UFMG, 2010b. [1995].

${ }^{13}$ Para uma leitura da linguagem e da soberania de acordo com o paradoxo da Teoria dos Conjuntos, ver Agamben (2010b [1995]). 
AGAMBEN, G. Une biopolitique mineure (Entrevista com Giorgio Agamben realizada por Stany Grelet e Mathieu Potte-Bonneville).Vacarme, n. 10, 2000.

AGAMBEN, G. O que resta de Auschwitz: o arquivo e a testemunha (Homo sacer III). Tradução de Selvino J. Assmann. São Paulo: Boitempo, 2008.

AGAMBEN, G. A comunidade que vem. Tradução de António Guerreiro. Lisboa: Editorial Presença, 1993.

BENVENISTE, É. Da subjetividade a linguagem. [1958]. In: BENVENISTE, É. Problemas de lingüística geral I. 5. ed. Tradução de Maria da Glória Novak e Maria Luiza Neri. Campinas, São Paulo: Pontes: Editora da UNICAMP, 2005. p.284293.

BUTTURI JUNIOR, A. A autoria, o dispositivo e a ética: os limites da (des) subjetivação na escrita. ALFA: Revista de Linguística, v. 60, n. 3, p. 507-530, 2016. Disponível em: http://www.scielo.br/pdf/alfa/v6on3/1981-5794-alfa-6o-3-0507. pdf. Acesso em: 15 out. 2018.

DELEUZE, G. Foucault. Tradução de Claudia Sant'Anna Martins. São Paulo: Brasiliense, 2005. [1986].

DELEUZE, G. O que é um dispositivo? In: Michel Foucault, filósofo. Barcelona: Gedisa, 1990, p. 155-161. Disponível em: http://vsites.unb.br/fe/tef/filoesco/ foucault/art14.pdf. Acesso em: 13 jul. 2012.

DERRIDA, J. Gramatologia. 2. ed. São Paulo: Perspectiva, 2008. [1967].

DERRIDA, J. A farmácia de Platão. Tradução de Rogério da Costa. 3. ed. São Paulo: Iluminuras, 2005.

DUARTE, A. Heidegger e Foucault, críticos da modernidade: humanismo, técnica e biopolítica. Trans/Form/Ação, São Paulo, v. 29, n. 2, p. 95-114, 2006.

FOUCAULT, M. O sujeito e o poder. In: Ditos e escritos IX: genealogia da ética, subjetividade e sexualidade. Tradução de Abner Chiquieri. Rio de Janeiro: Forense Universitária, 2014. [1982]. p. 118-140. 
FOUCAULT, M. O retorno da moral. In: Ditos e escritos V: ética, sexualidade e política. 2. ed. Tradução de Elisa Monteiro e Inês Autran Dourado Barbosa. Rio de Janeiro: Forense Universitária, 2010. [1984]. p. 252-263.

FOUCAULT, M. Sobre a história da sexualidade. In: FOUCAULT, M. Microfísica do poder. 27. ed. Tradução de Roberto Machado. Rio de Janeiro: Graal, 2009a. p. 243-276.

FOUCAULT, M. História da sexualidade I: a vontade de saber. 19. ed. Tradução de Maria Thereza Albuquerque e J. A. Guilhon Albuquerque. Rio de Janeiro: Edições Graal, 2009b. [1976].

FOUCAULT, M.A arqueologia do saber. Tradução de Luiz Felipe Baeta Neves. 8. ed. Rio de Janeiro: Forense Universitária, 2012. [1969].

HEIDEGGER, M. Ser e tempo: parte um. Tradução de Márcia de Sá Cavalcante. 6. ed. Rio de Janeiro, Petrópolis: Vozes, 1997. [1927].

NEGRI, A. Quando e como eu li Foucault. Tradução e organização Mario A. Marino. São Paulo: n-1, 2016. [2003].

SAUSSURE, F. de. Curso de lingüística geral. 4. ed. Tradução de Antonio Chelini, José Paulo Paes e Izidoro Blikstein. São Paulo: Cultrix, 1972. [1916].

\section{Como citar}

BUTTURI JR, Atílio. É a linguagem um dispositivo? (ou olinguista enrubescido). Revista da Abralin, v. 17, n. 2, p. 350-375, 2018.

Recebido em 29/01/2019 e aceito em 25/03/2019 